\title{
Urethral meatus preserving ventral onlay augmentation urethroplasty for female urethral stricture: our technique with initial experience
}

\author{
Varun Kumar Katiyar ${ }^{1}$, Rajeev Sood ${ }^{1}$, Anurag Singla ${ }^{1}$, Hemant Kumar Goel ${ }^{1^{*}} \mathbb{0}$, Nikhil Khattar ${ }^{2}$ and \\ Varun Gunavanthe ${ }^{3}$
}

\begin{abstract}
Background: Female urethral stricture (FUS) is an uncommon cause of lower urinary tract symptoms (LUTS) in women. Reconstructive techniques are being increasingly used for strictures resistant to the more conservative form of management. Most forms of reconstruction require cutting open of urethral meatus, thereby resulting in some loss of the meatus function. We hereby describe the technique of urethral meatus sparing ventral onlay mucosal graft augmentation urethroplasty with our initial experience.
\end{abstract}

Methods: We performed this procedure in 10 cases of FUS with normal meatus and prospectively studied the outcomes over a period of 6 months follow-up.

Results: There was 90 percent success rate with one recurrence. The mean Qmax increased from 7.2 to $19.5 \mathrm{ml} / \mathrm{s}$, mean post-void residual urine (PVRU) decreased from 96.5 to $22.7 \mathrm{ml}$ and the mean IPSS decreased from 26.1 to 5.7. There were no major complications noted and the patients demonstrated significant subjective and objective improvement of symptoms in the follow-up period.

Conclusion: The technique of meatus sparing ventral onlay augmentation graft urethroplasty is a promising approach with good outcomes, is reproducible and has minimal complication rate.

Keywords: Ventral onlay, Meatus sparing, Female urethral stricture, Augmentation urethroplasty, Substitution urethroplasty

\section{Background}

Female urethral stricture (FUS) is an uncommon cause of lower urinary tract symptoms (LUTS) in women [1-5]. The management strategies for it are still under a process of constant refinement and evolution. Strictures refractory to more conservative forms of treatment such as repeated urethral dilatations are now being increasingly managed by surgical reconstructive techniques $[6,7]$. A variety of surgical reconstructive approaches have been

\footnotetext{
${ }^{*}$ Correspondence: hemant.doc81@gmail.com

1 Department of Urology, ABVIMS \& Dr Ram Manohar Lohia Hospital,

Room No 31, New Delhi, India

Full list of author information is available at the end of the article
}

described with most of them including the use of grafts to augment the stricture site [8-12].

The two main approaches for augmentation urethroplasty are the dorsal (anterior wall) onlay and the ventral (posterior wall) onlay. Ventral onlay graft urethroplasty in FUS has been used less due to theoretical risk of urethrovaginal fistula. This approach has potential advantages such as avoidance of dissection around dorsal neurovascular bundle and dorsal sphincter complex, operating in a relatively avascular field and familiarity to urogynecologists $[13,14]$. Potential disadvantages are theoretical possibility of urethrovaginal fistulae, creation of hypospadiac meatus (when meatus is not preserved) $[14,15]$. While the increased risk of 
urethrovaginal fistula has not been substantiated, the meatus can very well be preserved in the majority of cases of FUS. We describe this technique of urethral meatus sparing ventral onlay graft augmentation urethroplasty in FUS with our initial experience.

\section{Methods}

The study was approved by the institution ethics board and conforms to principles of declaration of Helsinki. All patients provided written informed consent along with guarantees of confidentiality.

\subsection{Patient selection}

Ten consecutive female patients with diagnosed FUS with normal urethral meatus were included in the study, performed between September 2017 and October 2019. Uroflowmetry, Micturating Cystogram (MCU) and Urodynamic testing (UDS) were done in all cases to document bladder outlet obstruction. A preoperative urethroscopy with 6 Fr ureteroscope was done to document normal meatus and location and extent of urethral stricture (Fig. 1).

\subsubsection{Surgical technique}

The procedure was performed under regional or general anaesthesia depending on the choice of graft

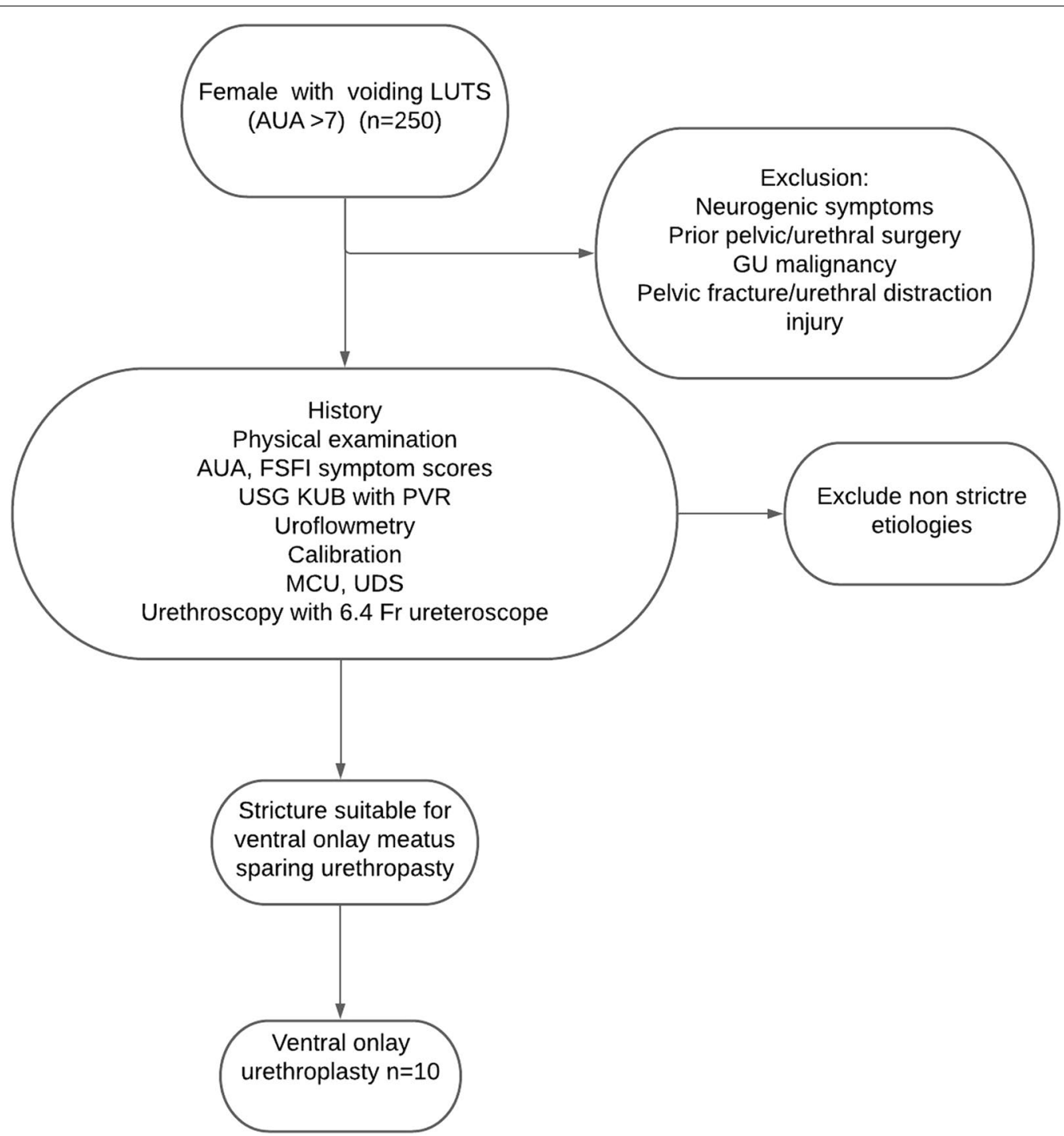

Fig. 1 Flow of the study. AUA (American Urology Association Symptom Score), FSFI (Female Sexual Function Index), SD (Standard Deviation), PVR (Post void residual volume), MCU(Micturating cystourethrogram), UDS (Urodynamic study) 
(vaginal or buccal mucosa). We used buccal or vaginal mucosal graft for the purpose of reconstruction, depending on the state of buccal and vaginal mucosa, history of tobacco chewing and patient preference. Vaginal douching (5\% povidone-iodine solution) or chlorhexidine gargles were started one night prior to surgery. The procedure was performed in the standard lithotomy with 20-degree Trendelenburg. An intraoperative urethroscopy was performed with a $6 \mathrm{Fr}$ ureteroscope, taking care not to dilate the stricture site, before passing a guidewire across the stricture. Urethra was approached through an inverted $U$-shaped incision made in the anterior vaginal wall with apex of ' $U$ ' near urethral meatus and base till bladder neck. Anterior vaginal wall flap including only the vaginal mucosa was developed to access ventral aspect of urethra. A transverse incision was then given on paraurethral tissue near urethral meatus and proximal paraurethral tissue flaps were raised to expose the ventral urethra. This layer was later used for quilting of graft and providing secure closure avoiding an overlapping suture line. With 14 French catheter in distal urethra as guide, ventral urethra was opened at distal end of stricture and extended proximally till healthy mucosa which could easily admit a 30 French dilator. The meatus was thus preserved in all cases where it was not involved. Three polyglactin 5-0 stay sutures were placed at the proximal healthy mucosa for easier subsequent placement of mucosal graft and a cystoscope confirmed adequacy of stricturotomy. A vagina or buccal mucosa of sufficient length and width corresponding to the stricturotomy was harvested. Our aim was to augment urethra to 30 Fr. For harvesting of vaginal graft, saline was injected submucosally in the posterolateral wall of vagina after marking the mucosa as per the required graft size. The underlying defect was sutured primarily with absorbable sutures after proper haemostasis. The buccal graft harvest site, when utilized, was left open to heal secondarily. Graft was de-fattened prior to its application. Meshing of graft was generally not required. The mucosal graft was now placed (with mucosal side making urethral lumen) and sutured to the opened urethral mucosa by making use of three preplaced polyglactin 5-0 sutures on proximal urethra by interrupted or continuous sutures and thus completing the closure on both sides sequentially. A 14/16 Fr catheter was then placed. Paraurethral tissue flap closure was done transversely over the urethra by continuous vicryl 4-0 suture. Each suture took paraurethral tissue flap on either side and graft tissue medially, thus doing external quilting of mucosal graft to paraurethral tissue layer. Anterior vaginal wall was closed by continuous vicryl 3-0 suture. Martius flap was placed between the paraurethral tissues and vaginal flap to ensure better soft tissue support, where vaginal mucosa was atrophic. A vaginal pack was then placed (Figs. 2,3).

\subsubsection{Post-op care and follow-up}

Vaginal pack was removed next morning and patient discharged on catheter on second postoperative day. Catheter was removed on postoperative day 21. Patients were asked to maintain perineal hygiene and avoid sexual intercourse for 3 months.

Patients were followed up by symptom assessment (IPSS) and uroflowmetry at 1 month, 3 months and 6 months post-surgery. Patient developing recurrence of symptoms or poor urine flow parameters was evaluated for recurrence of stricture. Sexual function by female sexual function index (FSFI) was also noted preoperatively and at 6 months.

Statistical analysis was done using Mann-Whitney U test; chi-square test; Wilcoxon singed-rank test.

\section{Results}

The preoperative parameters as well as postoperative outcomes in our series of 10 patients who underwent meatus sparing urethroplasty is given in Table 1 . The average age of patients in our series was $48 \pm 10.80$ years (range $35-63)$. The average length of stricture was $1.7 \pm 0.67 \mathrm{~cm}$ (range $0.5-3 \mathrm{~cm}$ ). The mean duration of surgery was $69.5 \pm 12.35 \mathrm{~min}$ (range $55-90 \mathrm{~min}$ ). We used buccal graft in seven of the patients and vaginal graft in three patients. Patients were discharged by postoperative day three and catheter was removed three weeks post-surgery in all of patients. We did not perform a routine pericatheter RGU before catheter removal.

Patients were subsequently followed up on outpatient basis with symptom scores and uroflowmetry with PVRU assessment. Figure 4 depicts the preoperative and postoperative uroflowmetry of the subject. We did not perform routine follow-up MCU or UDS in patient as long as they were asymptomatic with a non-obstructive uroflow.

None of the patient presented with any postoperative dyspareunia or new onset sexual dysfunction. There was a mean improvement in FSFI scores of about four points over baseline which was sustained throughout the follow of period of 6 months. There were no significant intraoperative or postoperative complications. None of the patients developed any de novo stress urinary incontinence. There was no incidence of local infection or urethrovaginal fistula.

One patient developed recurrence and presented with voiding LUTS along with poor flow rate $(11 \mathrm{ml} / \mathrm{s})$ and high PVR $(50 \mathrm{ml})$ at 2 months post-surgery. She was subjected to urethroscopy and diagnosed with recurrent 

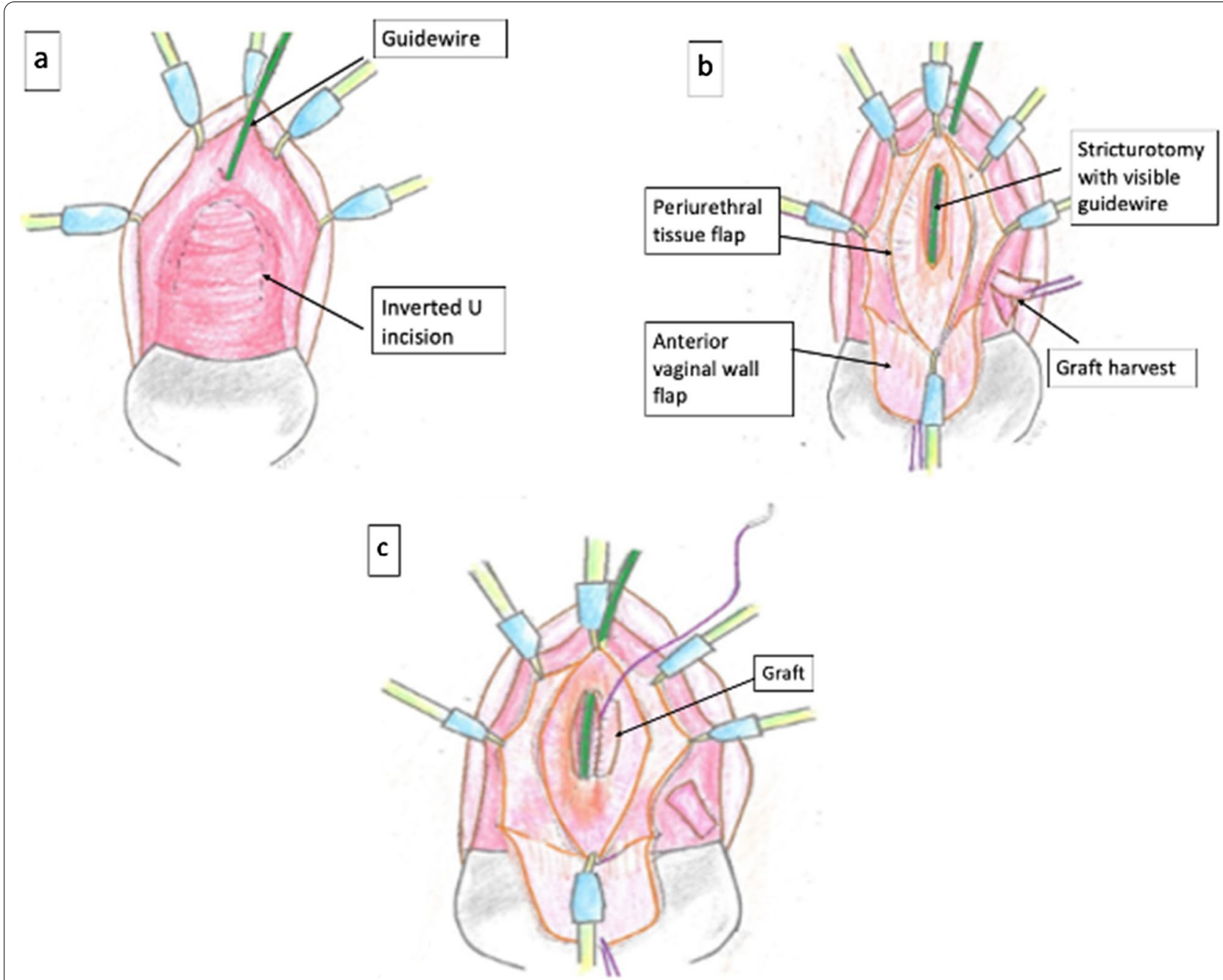

Fig. 2 Schematic depiction of technique a inverted U Incision, $\mathbf{b}$ incision of ventral strictured urethra and Graft harvest from posterolateral vaginal wall, c Graft placement and anastomosis [With permission from Goel H.K., Katiyar V., Gunavanthe V. (2021). Figure 15.1, 15,4, 15.5. Ventral (Posterior) Onlay Augmentation Urethroplasty for Female Urethral Stricture. In: Khattar N., Nayyar R., Panda A. (eds) Female Bladder Outlet Obstruction and Urethral Reconstruction. Springer, Singapore. https://doi.org/10.1007/978-981-15-8521-0_15]

short segment narrowing of urethral lumen at proximal anastomotic junction of urethral mucosa and the grafted mucosa. She was managed with internal urethrotomy and kept on self-calibration.

\section{Discussion}

FUS as a cause of female LUTS is an uncommon diagnosis and has long been under-recognized and undertreated. Most clinicians resort to repeated urethral dilatations which provide temporary relief at best [1618]. Augmentation urethroplasty is increasingly being considered as the preferred modality of recurrent FUS management. Many approaches for augmentation urethroplasty have been described, including the use of variety of flaps and grafts as inlay or onlay, in both dorsal and ventral placement $[12,13]$. Mucosal grafts are a good substitute for urethral mucosa, as they are built to survive in moist conditions, are resistant to infections and can be easily harvested. Buccal mucosa is our graft of choice in most conditions, as it is reported to give excellent results [15]. However, in patients with history of tobacco consumption or otherwise poor quality buccal mucosa or owing to patient preference, a vaginal graft provides a good source of tissue in ample quantities.

Amongst the two basic approaches, that is the dorsal and ventral, the ventral approach is by far more familiar to most urologists, as this is the plane in which most surgeons usually perform most uro-gynaecological procedures. It provides practical advantages of good visual exposure throughout the procedure with ease of 

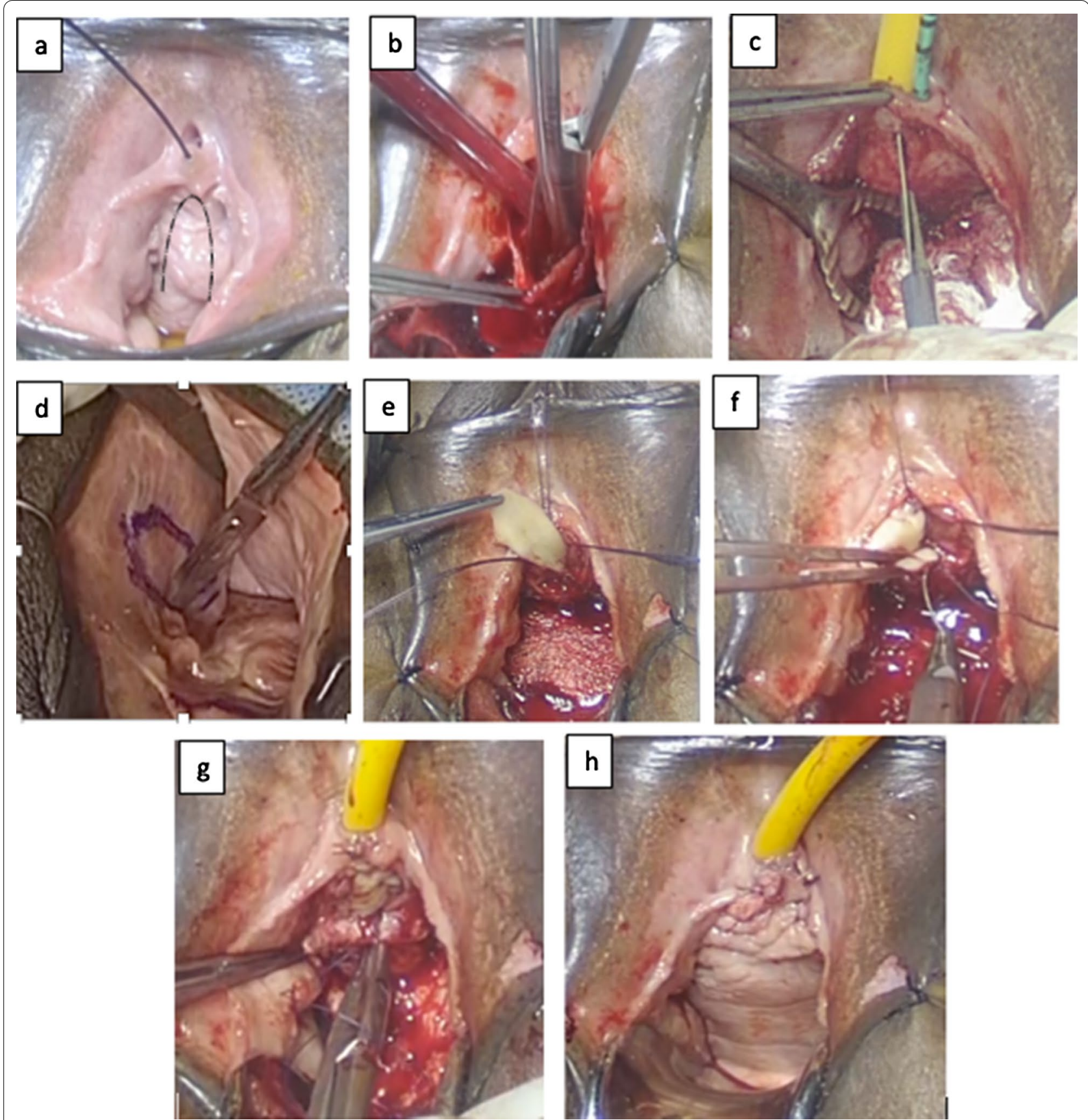

Fig. 3 intraoperative pictures, a inverted $U$ Incision on anterior vaginal wall $\mathbf{b}$ development of paraurethral flaps, $\mathbf{c}$ incision of ventral surface of strictured urethra, $\mathbf{d}$ Graft harvest, e Graft placement and anastomosis, $\mathbf{f}$ Completion of graft anastomosis, $\mathbf{g}$ Paraurethral tissue flap closure, $\mathbf{h}$ Anterior vaginal wall flap closure

dissection and stricture visualization. The theoretical advantages of the approach being avoidance of dissection near the neurovascular bundle, hence limiting chances of postoperative sexual dysfunction as well as intraoperative bleeding. The disadvantages of the ventral approach are the theoretically higher risk of urethrovaginal fistulas and the bothersome posteriorly directed and splayed urinary stream due to the resultant hypospadiatic meatus. As most of the strictures do not extend to meatus, we believe a meatus sparing approach to urethroplasty can be utilized in the majority of the cases and hence help avoid the major problem associated with ventral urethroplasty. 
Table 1 Comparison of preoperative and postoperative values of Qmax, PVRU, AUA symptom scores and FSFI scores. Qmax (Peak Flow Rate), PVRU (Post-void Residual Urine), AUA (American Urology Association Symptom Score), FSFI (Female Sexual Function Index), SD (Standard Deviation)

\begin{tabular}{lllccc}
\hline $\begin{array}{l}\text { Factors } \\
(\mathbf{n}=\mathbf{1 0})\end{array}$ & $\begin{array}{l}\text { Preoperative } \\
\text { Mean (SD) }\end{array}$ & $\begin{array}{l}\text { At 1 month } \\
\text { Mean (SD) }\end{array}$ & $\begin{array}{l}\text { At 3 month } \\
\text { Mean (SD) }\end{array}$ & $\begin{array}{l}\text { At 6 month } \\
\text { Mean (SD) }\end{array}$ & $\begin{array}{c}\text { p value } \\
\text { (preoperative and } \\
\mathbf{6} \text { month value) }\end{array}$ \\
\hline Qmax (ml/s) & $7.23(3.6)$ & $21.5(4.6)$ & $18.8(5.19)$ & $19.5(1.9)$ & 0.017 \\
PVRU (ml) & $96.5(116.3)$ & $23.2(23.5)$ & $23(14.3)$ & $22.7(11.4)$ & 0.04 \\
AUA Symptom Score & $26.1(1.5)$ & $7(3.0)$ & $7.2(4.49)$ & $5.7(1.5)$ & $<0.001$ \\
FSFI & $12.6(2.4)$ & Abstinence period & & $17.1(3.0)$ & 0.029 \\
\hline
\end{tabular}
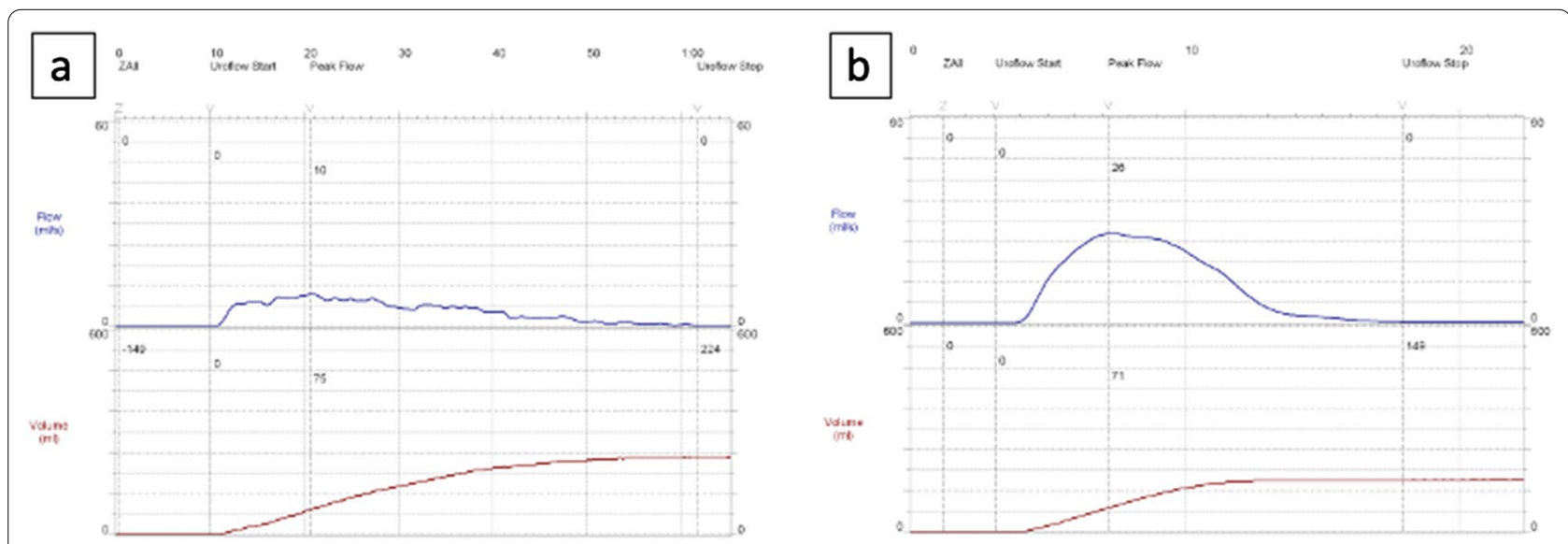

Fig. 4 Preoperative (a) \& postoperative (b) uroflowmetry of the patient

The wide exposure provided by the ventral approach to urethra greatly facilitates meatal preservation. Analogous to the well-established principals of male urethral reconstruction, where meatal preservation is done as far as possible, the reproduction of the same principles in female urethral reconstruction should yield favourable results. While a higher risk of urethrovaginal fistulas has not been noted in the ventral approach [13], the problem of a hypospadiatic meatus can be dealt with in these majority of the patients with such a meatus sparing approach. Contemporary series on female urethroplasty utilizing dorsal and ventral onlay graft augmentation techniques report high success rates varying between 85 and $95 \%[7,9,12,15,19]$. Our study notes a similar high success rate $(90 \%)$ and good functional outcomes with the use of meatus preservation technique.

Ozlulerden et al. [19] recently published an article detailing their technique of ventral augmentation urethroplasty in FUS. They retrospectively studied six cases and described their technique of placing a buccal graft in a ventral onlay manner after accessing the urethra via an inverted U-shaped vaginal flap. Our technique follows the initial same basic approach to urethral stricture, with the key departure in our technique being our meatal sparing in cases of strictures which do not extend till the meatus. This obviates the need of a meatoplasty and avoids the stream-related complications postoperatively. They reported a $100 \%$ success rate for a median follow-up of 23 months. We had a similar high success rate of $90 \%$ in our study using a larger sample size with a relatively smaller follow-up.

We have also utilized the female sexual function index (FSFI), a 19 question-based self-reported questionnaire to evaluate the various aspects of the female sexual function, to study the sexual function in patients pre- and post-operatively. The preoperative FSFI score of 12.6 showed a substantial improvement to 17.1 postoperatively at 6 month follow-up. There was no sexual dysfunction in any of the patients, with no development of dyspareunia, sensory abnormality or any other related complaint. This improvement of FSFI of about four points over the preoperative baseline could be due to resolution of inflammation of urethra as flows normalize. Manasa et al. [20] in their series similarly studied sexual function preoperative and post-operatively with the help of the FSFI questionnaire after dorsal onlay mucosal graft urethroplasty in 13 patients of urethral stricture. They reported improvement in sexual function in all cases of 
successful repair in contradiction to the theoretically held belief of a potential sexual dysfunction secondary to possible iatrogenic injury to the dorsal neurovascular bundle with the dorsal approach. We found a similar trend towards definite improvement in sexual function post-urethroplasty in all our patients.

\section{Conclusion}

Exact incidence of FUS is unknown but it is definitely ignored and undertreated. Repeated urethral dilatations is not always the right strategy for FUS. Our technique of meatal sparing ventral onlay mucosal graft augmentation urethroplasty yields good outcomes with a high success rate (90\%), low recurrence and low complication rates with minimal morbidity. Its key advantage of preservation of meatus and its functions support a strong consideration for utilization of our meatus preservation technique of urethroplasty and avoiding unnecessary sacrifice of the meatus in the vast majority of urethral stricture cases. The advantages of meatus preservation need to be further validated in studies involving direct comparison between different techniques of reconstruction.

\section{Abbreviations}

FUS: Female urethral stricture; LUTS: Lower urinary tract symptoms; Qmax: Maximal flow rate; AUA: American urology association symptom score; FSFI: Female sexual function index; USG: Ultrasonography; MCU: Micturating cystourethrogram; UDS: Urodynamic study; PVR: Post void residual volume.

\section{Acknowledgements}

None.

\section{Authors' contributions}

All authors have contributed significantly to the manuscript. All authors read and approve the final manuscript. VKK made significant contribution to conception, acquisition of data, analysis, drafting the work. RS made significant contribution to conception and drafting the work. AS made significant contribution to conception, acquisition, analysis, drafting the work. HKG made significant contribution to conception, acquisition, analysis, drafting the work. NK made significant contribution to conception, analysis, drafting the work. VG made significant contribution to conception, acquisition, drafting the work. All authors read and approve the final manuscript and to any substantially modified version that involves the author's contribution to the study, and agree both to be personally accountable for the author's own contributions and ensure that questions related to the accuracy or integrity of any part of the work, even ones in which the author was not personally involved, are appropriately investigated, resolved, and the resolution documented in the literature.

\section{Funding}

None.

\section{Availability of data and material}

All data pertaining to study are available with the author and would be provided on request.

\section{Declarations}

\section{Ethics approval and consent to publish}

The study was approved by the institutional ethics committee ("Post Graduate Institute of Medical Education and Research Institutional Ethics Committee" belonging to ABVIMS \& Dr RML Hospital), Ethics approval number: IEC/ PGIMER/RMLH/2096. All patients provided written informed consent along with guarantees of confidentiality.

\section{Consent for publication}

Written informed consent to participate and for publishing of study was obtained from all participants.

\section{Competing interests}

The authors have no conflict of interest to declare.

\section{Author details}

1'Department of Urology, ABVIMS \& Dr Ram Manohar Lohia Hospital, Room No 31, New Delhi, India. ${ }^{2}$ Medanta The Medicity, Gurgaon, Haryana, India.

${ }^{3}$ Bombay Hospital, Mumbai, India.

Received: 31 May 2021 Accepted: 29 August 2021

Published online: 08 September 2021

\section{References}

1. Malde S, Solomon E, Ockrim JL et al (2015) Female bladder outflow obstruction: an increasing but under-diagnosed phenomenon. Eur Urol Sup 14:2

2. Carr LK, Webster GD (1996) Bladder outlet obstruction in women. Urol Clin North Am 23:385-391

3. Spilotros M, Malde S, Solomon E et al (2017) Female urethral stricture: a contemporary series. World J Urol 35:991-995

4. Groutz A, Blaivas JG, Chaikin DC (2000) Bladder outlet obstruction in women: definition and characteristics. Neurourol Urodyn 19:213-220

5. Kuo HC (2005) Videourodynamic characteristics and lower urinary tract symptoms of female bladder outlet obstruction. Urology 66:1005-1009

6. Blaivas JG, Santos JA, Tsui JF et al (2012) Management of urethral stricture in women. J Urol 188:1778-1782

7. Smith AL, Ferlise VJ, Rovner ES (2006) Female urethral strictures: successful management with long-term clean intermittent catheterization after urethral dilatation. BJU Int 98:96-99

8. Tanello M, Frego E, Simeone C, Cosciani Cunico S (2002) Use of pedicle flap from the labia minora for the repair of female urethral strictures. Urol Int 69:95-98

9. Kowalik C, Stoffel JT, Zinman L, Vanni AJ, Buckley JC (2014) Intermediate outcomes after female urethral reconstruction: graft vs flap. Urology 83:1181-1185

10. Osman NI, Mangera A, Chapple CR (2013) A systematic review of surgical techniques used in the treatment of female urethral stricture. Eur Urol 64:965

11. Osman NI, Chapple CR (2015) Contemporary surgical management of female urethral stricture disease. Curr Opin Urol 25:341-345

12. Migliari R, Leone P, Berdondini E, De Angelis M, Barbagli G, Palminteri E (2006) Dorsal buccal mucosa graft urethroplasty for female urethral strictures. J Urol 176:1473-1476

13. Gozzi C, Roosen A, Bastian PJ, Karl A, Steif C, Tritschler S (2011) Volar onlay urethroplasty for reconstruction of female urethra in recurrent stricture disease. BJU Int 107:1964-1966

14. Colleselli K, Stenzl A, Eder R, Strasser H, Poissel S, Bartsch G (1998) The female urethral sphincter: a morphological and topographical study. J Urol 160:49-54

15. Sharma GK, Pandey A, Bansal H et al (2010) Dorsal onlay lingual mucosal graft urethroplasty for urethral strictures in women. BJU Int 105(9):1309-1312

16. Defreitas GA, Zimmern PE, Lemack GE, Shariat SF (2004) Refining diagnosis of anatomic female bladder outlet obstruction: comparison of pressure-flow study parameters in clinically obstructed women with those of normal controls. Urology 64:675-679

17. Santucci RA, Payne CK, Anger JT, Saigal CS (2008) Office dilation of the female urethra: a quality of care problem in the field of urology. J Urol 180:2068-2075

18. Schwender CE, Ng L, McGuire E, Gormley EA (2006) Technique and results of urethroplasty for female stricture disease. J Urol 175:976-980 
19. Yusuf O, Sinan C, Ali Z, Zafer A (2020) Female buccal mucosa graft urethroplasty: a new modified ventral onlay "AZ" technique. Int Urogynecol J. https://doi.org/10.1007/s00192-020-04354-w

20. Manasa T, Khattar N, Tripathi M, Varshney A, Goel H, Sood R (2019) Dorsal onlay graft urethroplasty for female urethral stricture improves sexual function: Short-term results of a prospective study using vaginal graft. Indian J Urol 35:267-272

\section{Publisher's Note}

Springer Nature remains neutral with regard to jurisdictional claims in published maps and institutional affiliations.

\section{Submit your manuscript to a SpringerOpen ${ }^{\odot}$ journal and benefit from:}

- Convenient online submission

- Rigorous peer review

- Open access: articles freely available online

- High visibility within the field

- Retaining the copyright to your article

Submit your next manuscript at $\boldsymbol{\nabla}$ springeropen.com 